
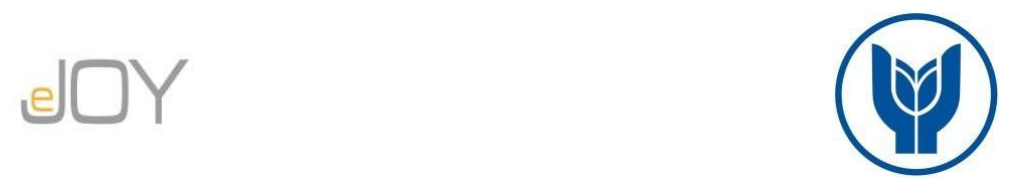

Arslan Çilhoroz, İ., Sivuk, D. / Journal of Yasar University, 2021, 16/62, 548-559

\title{
Ülkelerin Termal Turizm Harcamaları Bakımından Termal Turizm Verimliliklerinin Değerlendirilmesi
}

\section{Evaluation of Thermal Tourism Efficiency in Terms of Thermal Tourism Expenditures of Countries}

\author{
İlknur ARSLAN ÇiLHOROZ, Ankara Hacı Bayram Veli Üniversitesi, Türkiye \\ Orcid No: 0000-0003-4030-0158 \\ Derya SiVUK, Ankara Hacı Bayram Veli Üniversitesi, Türkiye \\ Orcid No: 0000-0002-6041-8551
}

\begin{abstract}
Öz: Termal turizminin gelişmesi ve sürdürülebilir bir rekabet ortamı yakalayabilmesi için termal turizm harcamalarının önemli bir yeri vardır. Bu çalı̧̧anin temel amacl, termal turizm kapsamında ilk 20 ülkenin verimlilik düzeylerini inceleyerek, verimlilik ile ilgili sorun yaşayan ülkelere çözüm önerilerinde bulunmaktır. Bu bağlamda ilk 20 ülke örnekleme alınarak amaçlı örnekleme yöntemi kullanılmıştır. Termal turizm harcamalarının verimliliği yedi girdi ve bir çıktı değişkeni yardımıyla Veri Zarflama Analizi (VZA) ile değerlendirilmiştir. VZA'nın Girdi Yönelimli CCR (Charnes, Cooper ve Rhodes-Ölçeğe Göre Sabit Getiri) ve BCC (Banker, Charnes ve CooperÖlçeğe Göre Değişken Getiri) modelleri kullanılmıştır. BCC Modeline göre kurgulanan modellemelerde ülkelerin yarısinin CCR Modeline göre kurgulanan modellemelerde ise ülkelerin $\% 10$ 'nun etkin olarak faaliyet gösterdiği tespit edilmişstir. Termal turizmde verimli olan ülkelerin ilk 20 sıralamasında mevcudiyetlerini korumak ve sürdürülebilir rekabet üstünlüğ̈̈ sağlayabilmek için termal tesislerini ve ülke olanaklarını geliştirmeye devam etmeleri gerekmektedir.
\end{abstract}

Anahtar Kelimeler: Termal Turizm, Termal Turizm Harcamalarl, Veri Zarflama Analizi, Verimlilik

$$
\text { JEL Siniflandirması:Z33, L83, D61, O12 }
$$

Abstract: Thermal tourism expenditures have an important role in the development of thermal tourism and achieving a sustainable competitive environment. The main purpose of this study is to examine the thermal tourism efficiency levels of the top 20 countries that provide thermal tourism services and to offer solutions for increasing efficiency for countries that have problems with efficiency. In the study, the first 20 countries serving within the scope of Thermal Tourism were sampled and a purposeful sampling method was used. The efficiency of these thermal tourism expenditures was evaluated with Data Envelopment Analysis (DEA) with the help of seven inputs and one output variable. VZA's input-oriented CCR (Charnes, Cooper and Rhodes-Fixed Scale Based on Scale) and BCC (Banker, Charnes and Cooper Variable Return by Scale) models were used. It was determined that half of the countries according to BCC model and 10\% of the countries according to CCR model operated effectively. It should continue to improve its thermal facilities and country facilities in order to maintain its presence in the top 20 rankings of countries that are efficient in these areas and to achieve sustainable competitive advantage.

Keywords: Thermal Tourism, Thermal Tourism Expenditures, Data Envelopment Analysis, Efficiency

JEL Classification: Z 33, L83, D61,O12

\section{Giriş}

Termal turizm, turistlerin termal banyolara, hidroterapi ve talasoterapi merkezlerine ziyaretlerini içeren, şifalı su kullanarak fiziksel ve zihinsel sağlıklarını düzeltmeyi amaçlayan alternatif bir turizm şeklidir. (Sfakianakis, 2000; Sarakiotis, 2012). 
Termal turizmin ortaya çıkışı ilk çağlara kadar dayanmaktadır. Ekonomik dururumu iyi olan kişiler, termal sulardan yararlanabilmek ve Akdeniz'in sağlıklı ikliminden faydalanarak şifa bulabilmek için seyahat etmişlerdir (Gray ve Poland, 2008). Termal sulardan elde edilen faydalar, özellikle Romalılar ve Yunanlılar tarafindan tarih boyunca ortaya koyulmuştur. (Chen ve diğerleri, 2013a).

Günümüzde insan sağlığı için önemli bir kaynak olduğunun farkına varan ülkelerin termal turizmi geliştirmeye yönelik çalışmaları her geçen gün artmaktadır. Cohen'e (2008) göre termal sektörün büyümesi, sürekli değişen ve gittikçe daha karmaşık bir küresel bağlamda, insan doğasından kaynaklanan fiziksel dinlenme ihtiyacına en açık tepki olarak anlaşılmaktadır. Termal turizmde konaklama süresinin fazla olması, mevsimsellik sorununun olmaması, yüksek istihdama katkıda bulunması, sağlığı iyileştirme etkinliklerin yanında, eğlence ve dinlenme imkânları sunması ve ekonomik yüksek katkı sağlaması, bu turizm çeşidine olan ilgiyi her geçen gün artırmaktadır (Zengin ve Eker, 2016: Öztürk ve Bayat, 2011: 147). Termal turizm kapsamında fiziksel bakım, konaklama, tedavi ve dinlenmeye yönelik aktiviteler gibi hizmetler tek başlarına bir gelir kaynağını yansıtmaktadır. Bu sebeple termal turizmin ekonomiye katkısı diğer turizm türlerin kıyasla daha fazladır. Termal tesisler ilk kurulduğunda fazla gideri olmasına rağmen maliyetini çok kısa bir zamanda karşılayan yatırım olarak bilinmektedir. Bununla birlikte termal sular vasıtasıyla şifa bulan hastaların ilaç kullanımında azalmalar olduğu için ülke ekonomisine de önemli ölçüde bir katkı sunmaktadır (Tengilimoğlu ve Karakoç, 2013).

Termal turizmi sağlık problemlerini ve cerrahiyi önlediği kabul edilen ve en çok kabul gören medikal turizme bir alternatif oluşturan hem sağlik faaliyetlerini destekleyen hem de sağlık dışı disiplinler kümesine dahil edilebilir (Harahsheh, 2002; Mueller ve Kaufmann, 2001; Chen ve diğerleri, 2013b; Silvestri ve diğerleri, 2017).GWI, termal / mineral kaynakları endüstrisini, özel mülklere sahip suların sağlık ve terapötik kullanımlarıyla ilişkili gelir getiren işyerlerini kapsayan bir alan olarak tanımlamaktadır. Buna göre 127 ülkede faaliyet gösteren 34.057 termal/maden suyu işletmesi olduğu tahmin edilmektedir. Bu işletmeler 2017 yılında 56,2 milyar dolar gelir elde etmiştir ve tahmini 1,8 milyon işçi çalıştırmaktadır (Global Wellness Institute, 2018).

Dünya'da termal turizm hizmetini karşılayan destinasyonların başında Almanya, Macaristan, Rusya, Fransa, İsviçre, İspanya, Japonya, Çek Cumhuriyeti, Slovak ve ABD gelmektedir (Tengilimoğlu ve Karakoç, 2013). Termal su kaynakları olan Kenya, Ruanda, Etiyopya, Suudi Arabistan, Kamboçya, Hindistan gibi ülkeler termal turizm sektörünü yeni ve değerli bir turizm alanı olarak geliştirme fırsatlarını fark etmeye başlamıştır. Çin, yeni kaplıca merkezlerine sürekli yatırım ve kaplıca merkezli turizmde güçlü bir büyüme göstermeye devam ederken, daha çok sağlık odaklı hizmetleri (Geleneksel Çin Tıbbı gibi) öncelikle eğlence amaçlı kaplıca tekliflerine aşılamaya çalışmaktadır. Termal / mineral kaynağı endüstrisi daha çok Asya Pasifik ve Avrupa bölgelerinde yoğunlaşmıştır. Asya Pasifik ve Avrupa birlikte sanayi gelirlerinin \% 95'ini ve işletmelerin \% 94'ünü oluşturmaktadır. Son zamanlarda (başta Çin'de olmak üzere) yaklaşık 450 yeni kuruluşun (işletme daha iyi olur) açılmıştır (Global Wellness Institute, 2018).

Dünya genelinde termal turizmin büyük bir ekonomiye sahip olduğu ve bu açıdan bu alanda yapılacak harcamaların ve yatırımların daha verimli kullanılması gerekliliği görüşü hakim olmaya başlamıştır (Global Wellness Institute, 2018). İlgili literatür incelendiğinde 
termal turizm verimliliğiyle ilgili çok az sayıda çalışmanın yapıldığı görülmektedir. Mihaliova (2016) tarafından yapılan çalışmada termal suların insanlar için tüm faydaları ve sağlık spalarında kullanımları göz önüne alınarak, sağlık otoritelerinin sağlık hizmetleri, eğlence aktiviteleri ve spa turizmi için kaplıcaları verimli kullanımı ile ilgili tedbirleri, politikaları ve faaliyetleri incelenmiştir. Termal turizm tesislerinin seçiminde etkili olan faktörler üzerine Emir ve Saraçli (2011) tarafından yapılan çalışmada; sağlık çalışanların nitelik ve yetkinliklerinin müşteri memnuniyeti için ikinci en önemli faktör olduğu belirlenmiştir. Sayili ve diğerleri (2007) tarafından yapılan çalışmada termal turistlerin, hane halkı geliri, geçmiş tecrübe, seyahat mesafesi, toplam sağlık harcama seviyeleri ile termal tesiste kalma süreleri arasında anlamlı ilişki bulmuşlardır. Ayrıca Önder ve diğerleri (2008) tarafından uluslararası turizm talebinin belirlemek amacıyla yapılan çalışmada kişi başına düşen gelir ve döviz kurları değişken olarak kullanılmıştır. McElroy (2006) tarafından yapılan çalışmada yükselen turizmin gelişiminin, artan gelir, göç, okuryazarlık ve yaşam beklentisi ve azalan işsizlik, doğurganlık ve bebek ölümleri ile ilişkili olduğu görülmüş̧ür. Yine Massidda ve Etzo (2012) tarafindan yapılan çalışmada kişi başına düşen gelirin turizm bölgelerinin seçilmesinde en önemli faktör olduğu sonucunu ortaya konulmuştur.

$\mathrm{Bu}$ çalışmanın temel amacı, termal turizm hizmeti veren ilk 20 ülkenin termal turizm verimlilik düzeylerini incelemek; verimlilik ile ilgili sorun yaşayan ülkeler için verimliliklerini arttırma noktasında çözüm önerilerinde bulunmaktır.

\section{Yöntem}

\subsection{Araştırmanın Amacı}

$\mathrm{Bu}$ çalışmanın temel amacı, termal turizm kapsamında ilk 20 ülkenin verimlilik düzeylerini inceleyerek, verimlilik ile ilgili sorun yaşayan ülkelere çözüm önerilerinde bulunmaktır.

\subsection{Araştırmanın Evren ve Örneklemi}

Çalışmada termal turizm kapsamında hizmet veren ilk 20 ülke örnekleme alınarak Amaçlı Örnekleme yöntemi kullanılmıştır.

\subsection{Araştırmanın Veri Toplama Yöntemi}

Global Welness Economy, OECD ve Dünya Bankası veri tabanı kullanılmış, veriler 20132015 ve 2017 yıllarını kapsamaktadır. Bunun nedeni, çalışma kapsamında incelenen değişkenlere ilişkin tam ve düzenli verilerin bu tarihler arasında ulaşılabilir olmasıdır.

\subsection{Araştırma Değiş̧kenleri}

Çalışma kapsamında kullanılan değişkenlere ilişkin bilgiler aşağıdaki tabloda (Tablo 1) yer almaktadır. Çalışmada kullanılan değişkenlere logaritmik dönüşüm uygulanmış olup, kısaltmaları parantez içlerinde belirtilmiştir. Bununla, değişkenlerin normalliği sağlanmıştır (Moody, 2009) 
Tablo 1. Değişkenlere İlişkin Açıklamalar

\begin{tabular}{|c|c|c|}
\hline \multicolumn{2}{|l|}{ Değişkenler } & Açıklamalar \\
\hline \multirow{7}{*}{ Girdi Değişkenleri } & Sağlık Harcaması & $\begin{array}{l}\text { Kişi Başı Sağlık Harcaması (US } \\
\text { Dolar) }\end{array}$ \\
\hline & Gelir & Kişi Baş1 Milli Gelir (GDP) \\
\hline & Hekim Sayıs1 & $\begin{array}{l}\text { Hekim Sayısı }(1000 \text { kişiye } \\
\text { düşen })\end{array}$ \\
\hline & Hemşire ve Ebe Sayısı & $\begin{array}{l}\text { Hemşire ve Ebe Sayı1 (1000 } \\
\text { kişiye düşen) }\end{array}$ \\
\hline & Okuryazar Oranı & $\begin{array}{l}\text { Toplam Nüfus } \\
\text { Okuryçindeki } \\
\text { Okur }\end{array}$ \\
\hline & Kur Değeri & $\begin{array}{l}\text { US Dolar Karşısında Kur } \\
\text { Değeri }\end{array}$ \\
\hline & Termal Turizm Merkez Sayısı & $\begin{array}{lcc}\text { Toplam Termal } & \text { Turizm } \\
\text { Merkezi Sayisi (Adet) } & \end{array}$ \\
\hline Çıktı Değişkeni & Termal Turizm Harcaması & $\begin{array}{lcc}\text { Ülkelerin } & \text { Toplam } & \text { Termal } \\
\text { Turizm Harcaması (US Dolar) }\end{array}$ \\
\hline
\end{tabular}

\subsection{Verilerin Analizi}

Verimlilik ölçümü, kuruluşlar verimliliği artırmak için mücadele ettikleri için büyük bir ilgi konusu olmuştur. Bu odaklanmanın nedenleri en iyi elli yıl önce Farrell (1957) tarafından üretken verimliliğin ölçümü hakkındaki klasik makalesinde belirtilmiştir. Farrell ayrıca, sorunu çözmek için yapılan tüm girişimlerin başarısız olmasının birincil nedeninin, çoklu girdilerin ölçümlerini tatmin edici herhangi bir verimlilik ölçüsünde birleştirememesinden kaynaklandığını belirtti. Bu yetersiz yaklaşımlar, tek bir girdi için ortalama bir üretkenlik oluşturmayı (diğer tüm girdileri göz ardı ederek) ve ağırlıklı bir girdi ortalaması ile çıktıyla karşılaştırılan bir verimlilik endeksinin oluşturulmasını içermektedir (Cook ve Selfrod, 2009). Bu da Veri Zarflama Analizi'nin gerekliliği ortaya çıkarmaktadır.

Bu çalışmada Veri Zarflama Analizi (VZA) gerçekleştirilmiştir. Analiz için 7 tanesi girdi, 1 tanesi ise çıktı değişkenler olarak belirlenmiştir. Uygulamada VZA'nın hem girdi yönelimli hem de çıktı yönelimli CCR ve BCC yöntemlerinin ikisi de kullanılmıştır. VZA en iyi uygulama gruplarını oluşturmak ve en iyi uygulama gruplarıyla kıyaslandığında hangi birimlerin verimli olmadığını ve bu verimsizliğin büyüklügünü belirlemek için kullanılan niceliksel bir tekniktir (Sherman ve Zhu, 2006).

Charnes, Cooper ve Rhodes (1978) tarafindan sunulan veri zarflama analizi (VZA), bir n karar verme biriminin (DMU) nispi verimliliğini değerlendirmek için kullanılan parametrik olmayan bir ekstremal yöntemdir (Boljunčić, 2006). VZA ayrıca modern ekonominin temel taşı olan üretim fonksiyonları ve / veya verimli üretim imkanı yüzeyleri gibi aşırı ilişkilerin ampirik tahminlerini elde etmenin yeni bir yolunu sunmaktadır (Adler vd., 2002). VZA, göreli performans1 iyi olan karar verme birimlerine 1, diğerlerine 1'den düşük skorlar atayan karmaşık ve tanımlanması zor çıktılara sahip sektörlerde kullanılan, bir analizdir (Boles vd., 1995; Laplante ve Paradi, 2015; Ekiz ve Tuncer Şakak, 2020). VZA, verimli olmayan birim için verimli birimlerden oluşan bir referans kümesi sunar. Referans olarak gösterilen bu birimler göreli olarak etkin olup benzer girdi ve çıtı kombinasyonuna sahiptir ve etkin olmayan birime çalışması için iyi operasyon uygulamaları örneklemektedir (Boussofiane vd., 1991). 
VZA'da temel de iki modelden kullanılmaktadır. Bu modeller, "girdiye yönelik" ve "çıktıya yönelik" olmak üzere iki grupta incelenebilir. Bunlardan ilki, Charnes, Cooper ve Rhodes (1978) tarafından geliştirilen CCR modelidir (Ghasemi vd., 2000). Bu model, ölçeğe göre sabit getiri varsayımı altında karar birimlerinin toplam etkinlik skorlarını hesaplamaktadır. Toplam etkinlik skoru, teknik etkinlik ve ölçek etkinliği değerlerinin çarpımıdır ve kaynakları belirleyerek, yetersiz olanları tahmin etmektedir (Behdioğlu ve Özcan, 2009).

Daha sonra Banker ve ark. (1984) VZA’nın ölçekten değişken getiri formunu (Variable Return Scale) geliştirmiş ve bu model BCC (Banker, Charnes ve Cooper'in isimlerinin baş harfleri) modeli olarak literatüre geçmiştir (Wang vd., 2008). Hem CCR, hem de BBC modelleri girdi veya çıktı yönelimli olarak belirlenebilmektedir (Çıtak, 2008).

Girdi Yönelimli CCR ve BCC modellerinin matematiksel ifadesinde kullanılan belirteçler, parametreler ve değişkenler aşağıda açıklanmıştır (İbiş, 2009);

\section{Belirteçler:}

$\mathrm{j}$ : çalışmada kullanılan karar verme birimlerinin sayısı

i: girdi say1s1

r: çıktı sayısı

\section{Parametreler:}

$$
\begin{gathered}
\mathrm{v}_{\mathrm{i}}: \text { girdi ağırlığ } 1(\mathrm{j}=1, \ldots, \mathrm{m}) \\
\mathrm{u}_{\mathrm{r}}: \text { çıktı ağırlığ } 1(\mathrm{i}=1, \ldots, \mathrm{s})
\end{gathered}
$$

\section{Değişkenler:}

$\mathrm{x}_{\mathrm{ij}}$ : j. karar verme biriminin i. girdisinin ağırlığ

$\mathrm{v}_{\mathrm{rj}}$ j. karar verme biriminin r. çıktısının ağırlı̆̆

Bir karar biriminin verimsiz olduğu kanıtlanırsa, diğer verimli birimlerin bir kombinasyonu aynı girdi bileşimi için daha büyük çıktı üretebilir, aynı çıktı bileşimini üretmek için daha az girdi veya ikisinin bir kombinasyonunu kullanabilir. Varsayımsal bir karar verme birimi, k0, verimsiz birim $\mathrm{k}$ için etkin referans seti olarak adlandırılan verimli birimlerin bir toplamı olarak oluşturulabilir (Adler vd., 2000).

Doğrusal programın ikili probleminin çözümü, k0'1 derlemek için gereken çarpanları doğrudan hesaplar: Girdi Yönelimli CCR Modeli (Konca vd., 2018):

$$
\begin{aligned}
& \text { Amaç Fonksiyonu; Max }=\sum_{r=1}^{s}\left(u_{r} y_{r j o}\right) \\
& \text { Kısıtlar; } \sum_{r=1}^{s}\left(u_{r} y_{r j}\right)-\sum_{j=1}^{m}\left(v_{i} x_{i j}\right) \leq 0 ; \sum_{i=1}^{m}\left(v_{i} x_{i j o}\right)=1
\end{aligned}
$$

$\mathbf{u}_{\mathbf{r}}, \mathbf{v}_{\mathbf{i}} \geq \mathbf{0}$

$\mathrm{r}=1, \ldots, \mathrm{s}$

$\mathrm{i}=\mathbf{1}, \ldots, \mathrm{m}$

Girdi Yönelimli BCC Modeli (Konca vd., 2018);

$$
\begin{aligned}
& \text { Amaç Fonksiyonu; } \operatorname{Max}=\sum_{r=1}^{s}\left(u_{r} y_{r j o}\right)+C_{o} \\
& \text { Kısıtlar; } \sum_{r=1}^{s}\left(u_{r} y_{r j}\right)-\sum_{j=1}^{m}\left(v_{i} x_{i j}\right)+C_{o} \leq 0 ; \sum_{i=1}^{m}\left(v_{i} x_{i j o}\right)=1
\end{aligned}
$$

$\mathrm{u}_{\mathrm{r}}, \mathrm{v}_{\mathrm{i}} \geq 0$

$\mathrm{r}=1, \ldots, \mathrm{s}$ 
$\mathrm{i}=1, \ldots, \mathrm{m}$

$\mathrm{C}_{\mathrm{o}}=$ serbest

Çalışma verileri VZA DEA-SOLVER 13 Programı kullanılarak analiz edilmiştir.

\section{Bulgular}

Analiz için VZA'nın hem girdi hem de çıktı yönelimli CCR ve BCC modelleri kullanılarak hem girdilerin hem de çıktıların optimizasyonu amaçlanmıştır. Analiz sonucunda ülkelerin termal turizme ait tanımlayıcı istatistikler Tablo'2 yer almaktadır.

Tablo 2. Değișkenlere İlişkin Tanımlayıcı İstatistikler

\begin{tabular}{|c|c|c|c|c|c|c|}
\hline \multirow{2}{*}{ Değişkenler } & \multicolumn{3}{|l|}{ Ortalama } & \multicolumn{3}{|c|}{ Standart Sapma } \\
\hline & 2013 & 2015 & 2017 & 2013 & 2015 & 2017 \\
\hline $\begin{array}{l}\text { Sağlık_Harcaması } \\
(\$)\end{array}$ & $3.098,49$ & $3.293,54$ & $3.551,53$ & $1.931,66$ & $2.105,80$ & $2.240,96$ \\
\hline GDP (\$) & $30.846,62$ & $28.365,93$ & $35.590,61$ & $18.936,22$ & $18.921,81$ & $21.399,37$ \\
\hline Hekim & 3,16 & 3,28 & 3,44 & 0,94 & 0,94 & 0,97 \\
\hline Hemşire & 7,86 & 8,09 & 8,26 & 3,72 & 3,77 & 3,78 \\
\hline Okuryazar & 97,87 & 98,20 & 98,41 & 1,98 & 1,77 & 1,44 \\
\hline Kur & 80,55 & 88,71 & 86,60 & 239,26 & 248,66 & 248,11 \\
\hline Termal_Merkez & 182,85 & 210,99 & 228,21 & 223,25 & 226,41 & 227,33 \\
\hline $\begin{array}{l}\text { Termal_Harcama } \\
(\$)\end{array}$ & $2.333,32$ & $2.381,01$ & $2.586,65$ & $3.898,40$ & $4.202,36$ & $4.524,59$ \\
\hline
\end{tabular}

Tablo 2'de göre termal sağlık harcaması ortalamasının yıllar itibariyle artış gösterdiği görülmektedir. 2013 y1lında 2333 \$ $( \pm 3898)$ olan ortalama 2017 y1lında 2586 \$ $( \pm 4524)$ olmuştur.

Tablo 3. Değişkenlere İlişkin Korelasyon Katsayıları

\begin{tabular}{|c|c|c|c|c|c|c|c|c|c|}
\hline \multirow{9}{*}{2013} & Değişkenler & $\begin{array}{l}\text { Sağlık } \\
\text { Harc. }\end{array}$ & GDP & Hekim & Hemşire & $\begin{array}{l}\text { Okur } \\
\text { yazar }\end{array}$ & Kur & $\begin{array}{l}\text { Terma } \\
\text { l } \\
\text { Merk. }\end{array}$ & $\begin{array}{l}\text { Termal_ } \\
\text { Har. }\end{array}$ \\
\hline & Sağlık Har. & 1,00 & & & & & & & \\
\hline & GDP & 0,86 & 1,00 & & & & & & \\
\hline & Hekim & 0,33 & 0,46 & 1,00 & & & & & \\
\hline & Hemşire & 0,68 & 0,78 & 0,35 & 1,00 & & & & \\
\hline & Okuryazar & 0,48 & 0,43 & 0,58 & 0,47 & 1,00 & & & \\
\hline & Kur & $-0,14$ & $-0,08$ & 0,24 & $-0,11$ & 0,05 & 1,00 & & \\
\hline & Termal Merk & $-0,15$ & $-0,14$ & 0,28 & $-0,13$ & 0,03 & $\begin{array}{l}- \\
0,02\end{array}$ & 1,00 & \\
\hline & Termal Har. & $-0,09$ & $-0,10$ & $-0,27$ & $-0,06$ & $-0,10$ & $\overline{-}, 10$ & $-0,16$ & 1,00 \\
\hline \multirow{7}{*}{2015} & Değişkenler & $\begin{array}{l}\text { Sağllk } \\
\text { Har. }\end{array}$ & GDP & Hekim & Hemşire & $\begin{array}{l}\text { Okur } \\
\text { yazar }\end{array}$ & Kur & $\begin{array}{l}\text { Terma } \\
\text { l } \\
\text { Mer. }\end{array}$ & $\begin{array}{l}\text { Termal } \\
\text { Harcam } \\
\text { a }\end{array}$ \\
\hline & Sağlık Harc. & 1,00 & & & & & & & \\
\hline & GDP & 0,87 & 1,00 & & & & & & \\
\hline & Hekim & 0,33 & 0,42 & 1,00 & & & & & \\
\hline & Hemşire & 0,68 & 0,80 & 0,39 & 1,00 & & & & \\
\hline & Okuryazar & 0,42 & 0,40 & 0,57 & 0,38 & 1,00 & & & \\
\hline & Kur & $-0,12$ & $-0,04$ & $-0,25$ & $-0,08$ & 0,15 & 1,00 & & \\
\hline
\end{tabular}




\begin{tabular}{|c|c|c|c|c|c|c|c|c|c|}
\hline & Termal Mer. & $-0,19$ & $-0,23$ & 0,14 & $-0,20$ & 0,03 & $\begin{array}{l}- \\
0,03\end{array}$ & 1,00 & \\
\hline & Termal Har. & $-0,10$ & $-0,13$ & $-0,23$ & $-0,08$ & $-0,12$ & $\begin{array}{l}- \\
0,09\end{array}$ & $-0,23$ & 1,00 \\
\hline \multirow{9}{*}{2017} & Değişkenler & $\begin{array}{l}\text { Sağlık } \\
\text { Har. }\end{array}$ & GDP & Hekim & Hemşire & $\begin{array}{l}\text { Okur } \\
\text { yazar }\end{array}$ & Kur & $\begin{array}{l}\text { Terma } \\
\text { l } \\
\text { Mer. }\end{array}$ & $\begin{array}{l}\text { Termal } \\
\text { Har. }\end{array}$ \\
\hline & $\begin{array}{l}\text { Sağlık_- } \\
\text { Harcaması }\end{array}$ & 1,00 & & & & & & & \\
\hline & GDP & 0,84 & 1,00 & & & & & & \\
\hline & Hekim & 0,29 & 0,45 & 1,00 & & & & & \\
\hline & Hemşire & 0,72 & 0,83 & 0,42 & 1,00 & & & & \\
\hline & Okuryazar & 0,41 & 0,39 & 0,54 & 0,42 & 1,00 & & & \\
\hline & Kur & $-0,11$ & $-0,09$ & $-0,24$ & $-0,05$ & 0,14 & 1,00 & & \\
\hline & Termal Merk. & $-0,19$ & $-0,22$ & 0,14 & $-0,20$ & 0,05 & $\begin{array}{l}- \\
0,04\end{array}$ & 1,00 & \\
\hline & Termal Har & 0,13 & $-0,16$ & $-0,16$ & $-0,09$ & $-0,09$ & $\begin{array}{l}- \\
0,09\end{array}$ & $-0,25$ & 1,00 \\
\hline
\end{tabular}

Tablo 3'de korelasyon katsayıları incelendiğinde en yüksek katsayı $(r=0,87) 2015$ yılında GDP ile sağlık harcaması arasında ortaya çıkmıştır. Buna göre gerçekleştirilecek analiz için herhangi bir sorunun olmadığı görülmüştür.

Tablo 4. Ülkelerin Termal Turizm Verimlilik Skorları

\begin{tabular}{|l|l|l|l|l|l|l|l|l|l|}
\hline \multirow{2}{*}{ Ülkeler } & \multicolumn{3}{l}{ BCC Modeli } & \multicolumn{3}{l}{ CCR Modeli } & \multicolumn{3}{l|}{ Ölçek Verimliliği } \\
\cline { 2 - 11 } & $\mathbf{2 0 1 3}$ & $\mathbf{2 0 1 5}$ & $\mathbf{2 0 1 7}$ & $\mathbf{2 0 1 3}$ & $\mathbf{2 0 1 5}$ & $\mathbf{2 0 1 7}$ & $\mathbf{2 0 1 3}$ & $\mathbf{2 0 1 5}$ & $\mathbf{2 0 1 7}$ \\
\hline Avusturya & 1,00 & 1,00 & 1,00 & 0,19 & 0,19 & 0,20 & 0,19 & 0,19 & 0,20 \\
\hline Brezilya & 1,00 & 1,00 & 1,00 & 0,04 & 0,06 & 0,08 & 0,04 & 0,06 & 0,08 \\
\hline Çin & $\mathbf{1 , 0 0}$ & $\mathbf{1 , 0 0}$ & $\mathbf{1 , 0 0}$ & $\mathbf{1 , 0 0}$ & $\mathbf{1 , 0 0}$ & $\mathbf{1 , 0 0}$ & $\mathbf{1 , 0 0}$ & $\mathbf{1 , 0 0}$ & $\mathbf{1 , 0 0}$ \\
\hline Çek Cumhuriyeti & 0,93 & 0,95 & 0,96 & 0,05 & 0,03 & 0,04 & 0,05 & 0,03 & 0,04 \\
\hline Fransa & 1,00 & 1,00 & 1,00 & 0,11 & 0,10 & 0,11 & 0,11 & 0,10 & 0,11 \\
\hline Almanya & $\mathbf{1 , 0 0}$ & $\mathbf{1 , 0 0}$ & $\mathbf{1 , 0 0}$ & $\mathbf{1 , 0 0}$ & $\mathbf{1 , 0 0}$ & $\mathbf{1 , 0 0}$ & $\mathbf{1 , 0 0}$ & $\mathbf{1 , 0 0}$ & $\mathbf{1 , 0 0}$ \\
\hline Macaristan & 0,93 & 0,94 & 0,94 & 0,05 & 0,04 & 0,04 & 0,05 & 0,04 & 0,05 \\
\hline İzlanda & 0,92 & 0,93 & 0,95 & 0,02 & 0,02 & 0,02 & 0,02 & 0,02 & 0,03 \\
\hline İtalya & 1,00 & 1,00 & 1,00 & 0,43 & 0,40 & 0,39 & 0,43 & 0,40 & 0,39 \\
\hline Japonya & 0,95 & 0,97 & 0,98 & 0,80 & 0,77 & 0,72 & 0,84 & 0,80 & 0,73 \\
\hline Polonya & 0,95 & 0,95 & 0,95 & 0,07 & 0,06 & 0,06 & 0,07 & 0,06 & 0,06 \\
\hline Portekiz & 1,00 & 1,00 & 1,00 & 0,09 & 0,07 & 0,08 & 0,09 & 0,07 & 0,08 \\
\hline Rusya & 0,93 & 0,94 & 0,95 & 0,25 & 0,19 & 0,21 & 0,27 & 0,20 & 0,22 \\
\hline Slovak cumhuriyeti & 1,00 & 1,00 & 1,00 & 0,09 & 0,09 & 0,11 & 0,09 & 0,09 & 0,11 \\
\hline Slovenya & 1,00 & 1,00 & 1,00 & 0,10 & 0,10 & 0,10 & 0,10 & 0,10 & 0,10 \\
\hline İspanya & 1,00 & 1,00 & 1,00 & 0,17 & 0,16 & 0,16 & 0,17 & 0,16 & 0,16 \\
\hline İsviçre & 0,99 & 1,00 & 1,00 & 0,06 & 0,07 & 0,07 & 0,06 & 0,07 & 0,07 \\
\hline Türkiye & $\mathbf{1 , 0 0}$ & $\mathbf{1 , 0 0}$ & $\mathbf{1 , 0 0}$ & $\mathbf{0 , 1 8}$ & $\mathbf{0 , 1 0}$ & $\mathbf{0 , 0 7}$ & $\mathbf{0 , 1 8}$ & $\mathbf{0 , 1 0}$ & $\mathbf{0 , 0 7}$ \\
\hline $\begin{array}{l}\text { Amerika } \\
\text { Devletleri }\end{array}$ & 0,99 & 1,00 & 1,00 & 0,07 & 0,09 & 0,12 & 0,07 & 0,09 & 0,12 \\
\hline Güney Kore & 0,96 & 0,95 & 0,96 & 0,02 & 0,02 & 0,02 & 0,02 & 0,02 & 0,02 \\
\hline
\end{tabular}
$\mathrm{CCR} / \mathrm{BCC}$ 
Tablo 4 incelendiğinde tüm yıllarda ve her iki modele göre de verimli bulunan ülkelerin Çin ve Almanya olduğu görülmüştür. Türkiye ise tüm yıllarda sadece BCC modeline göre verimli bulunmuştur. Ülkelerin BCC modelinde verimli bulunup CCR modelinde ise verimsiz bulunması normaldir. Bunun sebebi modellerin kendi doğası değişkenlerin ölçeğe göre sabit ve değişken özellik göstermesidir (Rödder ve Reucher, 2012).

Tablo 5. Ülkelerin Referans Gösterilme Sayıları

\begin{tabular}{|l|l|l|l|l|l|l|}
\hline \multirow{2}{*}{ Ülkeler } & \multicolumn{3}{l}{ BCC Modeli } & \multicolumn{2}{l|}{ CCR Modeli } \\
\cline { 2 - 7 } & $\mathbf{2 0 1 3}$ & $\mathbf{2 0 1 5}$ & $\mathbf{2 0 1 7}$ & $\mathbf{2 0 1 3}$ & $\mathbf{2 0 1 5}$ & $\mathbf{2 0 1 7}$ \\
\hline Avusturya & 3 & 1 & 1 & 2 & 2 & 2 \\
\hline Brezilya & 1 & 1 & 1 & 2 & 2 & 2 \\
\hline Çin & 1 & 1 & 1 & 1 & 1 & 1 \\
\hline Çek Cumhuriyeti & 2 & 2 & 2 & 1 & 1 & 1 \\
\hline Fransa & 1 & 3 & 1 & 2 & 2 & 2 \\
\hline Almanya & 1 & 1 & 1 & 1 & 1 & 1 \\
\hline Macaristan & 3 & 3 & 2 & 1 & 1 & 1 \\
\hline İzlanda & 2 & 2 & 2 & 1 & 1 & 1 \\
\hline İtalya & 1 & 1 & 1 & 2 & 2 & 2 \\
\hline Japonya & 2 & 2 & 2 & 1 & 1 & 1 \\
\hline Polonya & 4 & 3 & 4 & 2 & 2 & 2 \\
\hline Portekiz & 1 & 1 & 1 & 2 & 2 & 2 \\
\hline Rusya & 2 & 2 & 2 & 1 & 1 & 1 \\
\hline Slovak cumhuriyeti & 1 & 1 & 1 & 2 & 2 & 2 \\
\hline Slovenya & 1 & 1 & 1 & 2 & 2 & 2 \\
\hline İspanya & 1 & 1 & 1 & 2 & 2 & 2 \\
\hline İsviçre & 3 & 3 & 3 & 2 & 1 & 2 \\
\hline Türkiye & 1 & 1 & 1 & 2 & 2 & 2 \\
\hline $\begin{array}{l}\text { Amerika } \\
\text { Devletleri }\end{array}$ & 3 & 1 & 1 & 2 & 2 & 2 \\
\hline Güney Kore & 3 & 2 & 2 & 1 & 1 & 1 \\
\hline & & & & & & \\
\hline
\end{tabular}

Tablo 5'de ülkelerin diğer ülkelere referans gösterilme sayıları yer almaktadır. Buna göre, Polonya, Avusturya, Macaristan, İsviçre, ABD ve Güney Kore en fazla referans gösterilen ülkeler olmuştur.

\section{Tartışma ve Sonuç}

$\mathrm{Bu}$ çalışmada, termal turizm alanında ilk 20'ye giren ülkelerin verimlilik düzeyleri karşılaştırılmıştır. Analiz bulgularına göre, BCC Modeline göre kurgulanan modellemelerde ülkelerin yarısının CCR Modeline göre kurgulanan modellemelerde ise ülkelerin \%10'nun etkin olarak faaliyet gösterdiği tespit edilmiştir. BCC modeline göre verimli bulunan ülkeler; Avusturya, Brezilya, Çin, Fransa, Almanya, İtalya, Portekiz, Slovak Cumhuriyeti, Slovenya, İspanya ve Türkiye'dir. CCR modeline göre verimli bulunan ülkeler Çin ve Almanya'dır. Verimsiz olarak belirlenen ülkelerden en düşük etkinlik skorlarına sahip olan ülkeler BCC Modeline göre Macaristan, İzlanda ve Rusya, CCR Modeline göre ise Güney Kore, İzlanda ve Çek Cumhuriyeti olarak belirlenmiştir.

Literatür incelendiğinde termal turizmle ilgili birçok çalışma yapılmıştır. Kozak (1992) tarafindan termal turizmin önemini ortaya koymak amacıyla yapılan çalışmada termal turizm 
tesislerin yalnız sundukları ürün farklılığı ile değil, işletilmelerinde de kendilerine özgü pek çok özelliği olduğu ifade etmiştir. Gençay (2014) tarafından kurumsal performans karnesi yönteminin termal turizm işletmelerinde nasıl oluşturulabileceğine yol gösterdiğini ele aldığ çalışmada termal turizm işletmelerinin, sağlık ve turizm gibi iki farklı alandaki çok çeşitli birimleri ve kapsamlı hizmetleri tek çatı altında toplayan ve çok geniş bir alanı kapsayan kompleks tesisleri olduğu ifade etmişlerdir. Bu nedenlerle termal turizm işletmelerinde, hem sağlık hem de turizm alanında başarılı olabilmek için çok boyutlu ve kapsamlı bir ölçme ve değerlendirme sisteminin kurulması ve yönetim biçimi olarak benimsenmesinin gerektiği görülmektedir. Bu anlamda kurumsal performans karnesi modeli ve bu modelin kapsadığ birçok özellik termal turizm işletmelerinin yönetiminde sağlayacağı avantajlar olarak sayılmaktadır. Belkayalı (2009) tarafından yapılan çalışmada jeotermal kaynakların termal turizm değerini arttırmak için kaynakların koruma kullanma dengesi kurularak kullanılması gerektiğini ve yapılacak yatırımlarda jeotermal kaynağa sahip alanların turizm ve rekreasyon amaçlı kullanımının ekonomik değeri ve özellikle sağlık amaçlı kullanım değeri kesinlikle göz ardı edilmemesi gerektiği sonucuna ulaşmışlardır. Lim ve diğerleri (2015) tarafindan yapılan çalışmada turistlerin termal tesis seçerken memnuniyet oranlarını dikkate aldığını belirtmişlerdir. Silverstri ve diğerleri (2017) tarafından yapılan çalışmada termal tesislerde hizmet kalitenin teknik yönünde ve termal havuzun konforu, görünümü, temizliği ve güvenliği büyük önem arz ederken, fonksyinonel kalitede hizmet kalitesini önemli ölçüde etkileyen tek faktörün, çalışanların müşterilerinin ihtiyaçlarını anlayabilmeleri ve karş1layabilmeleri olduğunu öne sürmüştür. Medine-Muñoz ve Medine-Muñoz (2014) termal turizm sektöründeki sağlıklı yaşam destinasyonlarının çekiciliğini analiz etmiş ve termal yapılardaki personelin dikkatinin bu tür destinasyon seçimini etkileyen en önemli faktör olduğunu göstermiştir. Akgül (2020) termal işletmeler rekabet içerisinde, hizmet üretmeye çalışırken aynı zamanda müşteri memnuniyetini arttırırken, insan kaynakları yönetim teknikleri açısından personel güçlendirme ön plana çıkmaktadır. Bu işletmeleri, personeline yaptığı güçlendirme faaliyetleri sonrasında onların yaratıcılıklarının gelişmesine katkı sağladıklarında müşteri memnuniyetini arttırırken aynı zamanda rekabet avantajı sağlayacaklarını belirtmişlerdir. Çevrimli ve Beyhan (2020) tarafından yapılan çalışmada Çalışma, bölgedeki konaklama yapılarını farklı boyutlarıyla ele almış olup, yapıların güncel durumunu araştırmayı hedeflemiştir. Termal turizm yapılarının mimari biçimlenmesinde farklılaşmayı sağlayan unsurlar incelenerek konu özelinde şemalar oluşturulmuştur. Son olarak, Chen ve ark. (2013b) termal sektördeki müşteri hizmetlerinin sekiz önemli faktörünün personel hizmetlerini içermektedir. CI'ye bakıldığında, en önemli değişken, ciddiyet, güvenilirlik, kalite, dinleme yeteneği ve tüm resort spa'nın müşterilerinin ihtiyaçlarını karşılama taahhüdü olan ilişkisel kalite ile temsil edilmektedir.

$\mathrm{Bu}$ alanlarda verimli olan ülkelerin ilk 20 sıralamasında mevcudiyetlerini korumak ve sürdürülebilir rekabet üstünlüğü sağlayabilmek için termal tesislerini ve ülke olanaklarını geliştirmeye devam etmeleri gerekmektedir. Verimsiz bulunan ülkelerin ise termal merkez sayısı, verimli bulunan ülkelerden daha fazla gelişme kat etmelidir. Termal turizmde rekabet avantajı elde etmek için termal turizm işletmeleri pazar bölümlendirmesi yapabilir. Sektöre yeni girmek isteyen ülkeler, Çin ve Almanya gibi ülkelerin termal turizm stratejilerinden faydalanabilir. Stavroula ve Vasiliki (2020) tarafından yapılan çalışmada Almanya, Avrupa'da termal turizmin ana destinasyonların biri olduğunu ve Almanya'da 50 milyon geceleme ile 
yaklaşık 250 termal turizm merkezi faaliyet gösterdiğini ifade etmişlerdir. Ayrıca ülkede termal turizm sektöründe 350.000 işçi istihdam edilirken, üretilen yıllık gelirin 26 milyar euro olduğu tahmin edilmektedir. En fazla referans gösterilen ülkelerden olan Polonya ise sigortası olmayan hastaların ucuza tedavi alabileceği bir destinasyon olarak karşımıza çıkmaktadır.

$\mathrm{Bu}$ çalışmanın bulguları dikkate alındığında ülkelerin termal turizm özelinde sağlık turizmi verimliliklerinin değerlendirilmesinin gerekli olduğu görülmüştür. $\mathrm{Bu}$ bakımdan sağlık turistlerinin hem ülke hem de termal turizm olanaklarının seçiminde ülkelerinin verimliliklerinin yadsınamaz olduğu bilinmektedir. $\mathrm{Bu}$ nedenle, ülkelerin termal turizm verimliliklerini konu alan çalışmaların yapılması oldukça önem arz etmektedir. Bu çalışmada da termal turizm alanında ilk 20 sıralamasına giren ülkelerin verimlilikleri söz konusu çalışmanın literatürde önemli bir yer tutacağı ve termal turizm konusunda ülkelere yol gösterici olacağı düşünülmektedir.

Küreselleşmenin etkisiyle termal turizm pazarı da daha hızlı büyümeye başlamıştır. Termal turizmin gelişmekte olduğu belirli alanlarda, uygun ve modern tesisler ve altyapılar oluşturulmalı veya mevcut olanlar iyileştirilmelidir, bu kamu-özel ortaklıkları (PPP'ler) ile gerçekleştirilebilir. Ayrıca hastaların ve refakatçilerinin boş zamanlarında eğlendirilebilmesi için bu alanlarda başka aktiviteler de geliştirilmelidir.

Bununla birlikte çalışmanın birtakım sınırlılıkları da bulunmaktadır. İlk olarak, bu çalışma sadece termal turizmde en etkili 20 ülke ile sınırlıdır. Diğeri, ulaşılan sonuçlar bu çalışma kapsamında ele alınan bağımsız ve bağımlı değişkenlere göre değerlendirilmiştir. Son olarak, bu çalışmada sadece 2013, 2015 ve 2017 yıllarına ait verilere dayalı gerçekleştirilmiştir. VZA yapılırken farklı veri seti ve farklı yönelimlerin varsayıldığı modellerde farklı sonuçların ortaya çıkabileceği unutulmamalıdır. Ayrıca verimliliklerin değerlendirilmesi performans değerlendirmelerinin sadece bir boyutunu oluşturmaktadır. Gelecekteki çalışmalar, diğer ülkeleri ve sağlık turizmi harcamaları üzerindeki esneklik etkilerini dikkate alarak analizi genişletmelidir.

Gelecekteki çalışmalar, termal turizmi harcamaları üzerindeki özelliklerini ve turistlerin yurtdışında ne tür bir tedavi aradığını anlamak için ülkeye özgü anketler gibi diğer analiz tekniklerini de dikkate almalıdır. Gelişmiş ülkelere termal turizminin daha iyi anlaşılmasını sağlayabilir ve bu niş turizm üzerine yapılan ampirik çalışmaların ilerletilmesine katkıda bulunabilir. Yapılacak yeni çalışmalarda bu sınırlılıkların dikkate alınması ve daha geniş bir veri kümesi kullanılması çalışmaların kapsamını ve sonuçların genellenebilirliğini artırabilecektir. 


\section{KAYNAKÇA}

Adler, N., Friedman, L., \& Sinuany-Stern, Z. 2002. "Review of ranking methods in the data envelopment analysis context". European journal of operational research, 140(2), 249-265.

Akgül, V. 2020. “Gönen Termal Turizm Merkezindeki Otel İşletmelerinde Personel Güçlendirme ve Yaratıcılık İlişkisine Yönelik Bir Uygulama”. Journal of Yaşar University, 15(60), 790-805.

Behdioğlu, S., \& Özcan, G. 2009. "Veri Zarflama Analizi Ve Bankacılık Sektöründe Bir Uygulama”. Suleyman Demirel University Journal Of Faculty Of Economics \& Administrative Sciences, 14(3).

Belkayalı, N. 2009. "Jeotermal Enerji Kaynaklarının Sağlık, Turizm Ve Rekreasyon Amacıyla Kullanımı Ve Ekonomik Değerinin Tespiti”: Yalova termal kaplıcaları örneği. Düzenleyen Odalar.

Boles, J.S. \& N. Donthu \& R. Lohtia. 1995. "Salesperson Evaluation Using Relative Performance Efficiency: The Application of Data Envelopment Analysis". Journal of Personal Selling and Sales Management, 15(3), 31-49.

Boljunčić, V. 2006. "Sensitivity analysis of an efficient DMU in DEA model with variable returns to scale (VRS)". Journal of Productivity Analysis, 25(1-2), 173-192.

Boussofiane, A., Dyson, R. G., \& Thanassoulis, E. 1991. “Applied data envelopment analysis”. European journal of operational research, 52(1), 1-15.

Charnes, A., Cooper, W. W., \& Rhodes, E. 1978. "Measuring the efficiency of decision making units". European journal of operational research, 2(6), 429-444.

Chen, K. H., Liu, H. H., \& Chang, F. H. 2013. "Essential customer service factors and the segmentation of older visitors within wellness tourism based on hot springs hotels". International Journal of Hospitality Management, 35, 122-132.

Chen, K., Singla, A., Singh, A., Ramachandran, K., Xu, L., Zhang, Y., ... \& Chen, Y. 2013. “OSA: An optical switching architecture for data center networks with unprecedented flexibility". IEEE/ACM Transactions on Networking, 22(2), 498-511.

Cohen, M., \& Bodeker, G. 2008. "Understanding the global spa industry”. Spa management.-2008.

Cook, W. D., \& Seiford, L. M. 2009. "Data envelopment analysis (DEA)-Thirty years on”. European journal of operational research, 192(1), 1-17.

Çevrimli, A. B. A., \& Beyhan, Ş. G. 2020. “Termal Turizm Yapıları Özelinde Mimari Kimlik Analizi ve Etkileşim Şemasının Oluşturulması: Pamukkale-Karahayıt Örneği”. Journal of Advanced Research in Natural and Applied Sciences, 6(2), 283-302.

Çıtak, L. 2008. “Türkiye'deki Menkul Kıymet Yatırım Ortaklıklarının Etkinliklerinin Veri Zarflama Analizi İle Değerlendirilmesi”. Erciyes Üniversitesi İktisadi ve İdari Bilimler Fakültesi Dergisi, (31), 69-94.

Ekiz, M. K., \& Tuncer Şakar, C. 2020. "A new DEA approach to fully rank DMUs with an application to MBA programs". International Transactions in Operational Research, 27(4), 1886-1910.

Emir, O. \& Saraçli, S. 2011. "Determinants of customer satisfaction with thermal hotels". Anatolia-An International Journal of Tourism and Hospitality Research, 22(01), 56-68.

Gençay, İ. C. 2014. "Termal Turizm İşletmelerinde Kurumsal Performans Karnesi Oluşturulmasına Yönelik Model Önerisi”. Seyahat ve Otel İşletmeciliği Dergisi, 11(1).

Ghasemi, N., Najafi, E., Lotfi, F. H., \& Sobhani, F. M. 2020. "Assessing the performance of organizations with the hierarchical structure using data envelopment analysis": An efficiency analysis of Farhangian University. Measurement, 156, 107609.

Global Wellness Institute 2014. "Global, SPA \& Wellness Economy Monitor”. Global Wellness Institute Publication, USA.

Global Wellness Institute 2017. “Global Wellness Economy Monitor”. Global Wellness Institute Publication, USA.

Global Wellness Institute 2018. "Global Wellness Economy Monitor”. Global Wellness Institute Publication, USA.

Gray, H. H., \& Poland, S. C. 2008. "Medical tourism: crossing borders to access health care". Kennedy Institute of Ethics Journal, 18(2), 193-201.

Harahsheh, S. 2002. "Curative tourism in Jordan and its potential development". Bournemouth University, United Kingdom, 3(1), 45-78. 
İbiş, S. 2009. "Performance Measurement by Using Data Envelopment Analysis in Banking Industry: An Application” Dokuz Eylül Üniversitesi Sosyal Bilimler Enstitüsü, İngilizce İşletme Anabilim Dalı, Yüksek Lisans Tezi, İzmir.

Konca, M., Gözlü, M., \& Çakmak, C. 2019. “G-20 Ülkelerinin Sağlık Harcamaları Yönünden Etkinliğinin Değerlendirilmesi”. Verimlilik Dergisi, (2), 119-141.

Kozak, N. 1992. “Termal turizm işletmeciliği ve önemi”. Anatolia: Turizm Araştırmaları Dergisi, 3(3), 33-38.

LaPlante, A.E. \& J.C. Paradi 2015. "Evaluation of Bank Branch Growth Potential Using Data Envelopment Analysis", Omega, 52, 33-41.

Lim, Y. J., Kim, H. K., \& Lee, T. J. 2016. "Visitor motivational factors and level of satisfaction in wellness tourism: Comparison between first-time visitors and repeat visitors". Asia pacific journal of tourism research, 21(2), 137-156.

Massidda, C., \& Etzo, I. 2012. "The determinants of Italian domestic tourism: A panel data analysis". Tourism Management, 33(3), 603-610.

McElroy, J. L. 2006. "Small island tourist economies across the life cycle”. Asia Pacific Viewpoint, 47(1), 6177.

Medina-Muñoz, D. R., \& Medina-Muñoz, R. D. 2014. "The attractiveness of wellness destinations": An importance-performance-satisfaction approach. International Journal of Tourism Research, 16(6), 521533.

Mihaliova, N. 2016. "Efficiency of utilization of thermal and mineral waters". 52-53 in the Annual Report

Moody, C. 2009. "Basic econometrics with STATA. Economics Department". College of William and Mary.

Mueller, H., and Kaufmann, E. L. 2001. "Wellness tourism: Market analysis of a special health tourism segment and implications for the hotel industry". Journal of vacation marketing, 7(1), 5-17.

Öztürk, M ve Bayat, M. 2011. "Uluslararası Turizm Hareketlerinde Sağlık Turizminin Rolü ve Kalite Çalışmalarının Önemi Bir Literatür Çalışması”. Kahramanmaraş Sütçü İmam Üniversitesi İktisadi ve İdari Bilimler Fakültesi Dergisi, Arşiv: Cilt 1, Sayı 2, Cilt 1, Sayı 2, Sayfalar s.135 - 156 http://iibfdergisi.ksu.edu.tr/issue/10263/125877 18.04.2018

Rödder, W., \& Reucher, E. 2012. "Advanced X-efficiencies for CCR-and BCC-models-towards Peer-based DEA controlling”. European Journal of Operational Research, 219(2), 467-476.

Sarakiotis, A. 2012. "Balneotherapy - medical observations and applications". Retrieved June 20, 2018 from http://www.iama.gr/ethno/Therm/sarakiwt.html

Sayili, M., Akca, H., Duman, T., \& Esengun, K. 2007. "Psoriasis treatment via doctor fishes as part of health tourism: A case study of Kangal Fish Spring, Turkey”. Tourism Management, 28(2), 625-629.

Sfakianakis, M. (2000). Alternative Forms of Tourism. Athens: Hellenic.

Sherman, H. D., \& Zhu, J. 2006. "Service Productivity Management: Improving Service Performance Using Data Envelopment Analysis (DEA)". New York: Springer Science and Business Media.

Stavroula, G. ve Vasiliki, D. 2020. "Sürdürülebilir kalkınmanın alternatif biçimleri: termal turizm örneği”". Uluslararası Çevre ve Sürdürülebilir Kalkınma Dergisi, 19 (4), 367-377.

Silvestri, C., Aquilani, B., \& Ruggieri, A. 2017. "Service quality and customer satisfaction in thermal tourism". The TQM Journal.

Tengilimoğlu, D. ve Karakoç, G. 2013. “Termal Turizm ve SPA Turizm”. (Ed.) Tengilimioğlu, D. Sağlık Turizmi. Siyasal Kitabevi, Ankara.

Wang, J., Yan, R., Hollister, K., \& Zhu, D. 2008. "A historic review of management science research in China”. Omega, 36(6), 919-932.

Zengin, B. ve Eker, N. 2016. "Sakarya İli Termal Turizm Potansiyelinin Değerlendirilmesi". Kastamonu Üniversitesi İktisadi ve İdari Bilimler Fakültesi Dergisi, (13). 165-181 